\title{
Multifunctional dendrimer-based nanoparticles for in vivo MR/CT dual-modal molecular imaging of breast cancer
}

This article was published in the following Dove Press journal:

International Journal of Nanomedicine

18 July 2013

Number of times this article has been viewed

\author{
Kangan $\mathrm{Li}^{1,4,5, *}$ \\ Shihui Wen ${ }^{2, *}$ \\ Andrew C Larson ${ }^{4,5}$ \\ Mingwu Shen ${ }^{2}$ \\ Zhuoli Zhang ${ }^{4,5}$ \\ Qian Chen ${ }^{3}$ \\ Xiangyang $\mathrm{Shi}^{2,3}$ \\ Guixiang Zhang' \\ 'Department of Radiology, Shanghai \\ First People's Hospital, Shanghai \\ Jiaotong University School of \\ Medicine, Shanghai, People's \\ Republic of China; ${ }^{2}$ College of \\ Chemistry, Chemical Engineering and \\ Biotechnology, Donghua University, \\ Shanghai, People's Republic of \\ China; ${ }^{3}$ State Key Laboratory for \\ Modification of Chemical Fibers \\ and Polymer Materials, Donghua \\ University, Shanghai, People's \\ Republic of China; ${ }^{4}$ Departments of \\ Radiology and Biomedical Engineering, \\ Northwestern University, Chicago, IL, \\ USA; ${ }^{5}$ Robert $\mathrm{H}$ Lurie Comprehensive \\ Cancer Center, Chicago, IL, USA \\ *These authors contributed equally \\ to this work
}

Correspondence: Xianyang Shi 2999 North Renmin Road, Shanghai 201620, People's Republic of China

Tel +862I 67792656

Fax +86 21 67792306

Email xshi@dhu.edu.cn

Guiziang Zhang

100 Haining Road, Shanghai 200080,

People's Republic of China

Tel +86 2I 63240099 ext 4I66

Fax +86 21 67792306

Email guixiangzhang@sina.com

\begin{abstract}
Development of dual-mode or multi-mode imaging contrast agents is important for accurate and self-confirmatory diagnosis of cancer. We report a new multifunctional, dendrimer-based gold nanoparticle (AuNP) as a dual-modality contrast agent for magnetic resonance (MR)/computed tomography (CT) imaging of breast cancer cells in vitro and in vivo. In this study, amine-terminated generation 5 poly(amidoamine) dendrimers modified with gadolinium chelate (DOTA-NHS) and polyethylene glycol monomethyl ether were used as templates to synthesize AuNPs, followed by Gd(III) chelation and acetylation of the remaining dendrimer terminal amine groups; multifunctional dendrimer-entrapped AuNPs (Gd-Au DENPs) were formed. The formed Gd-Au DENPs were used for both in vitro and in vivo MR/CT imaging of human MCF-7 cancer cells. Both MR and CT images demonstrate that MCF-7 cells and the xenograft tumor model can be effectively imaged. The Gd-Au DENPs uptake, mainly in the cell cytoplasm, was confirmed by transmission electron microscopy. The cell cytotoxicity assay, cell morphology observation, and flow cytometry show that the developed Gd-Au DENPs have good biocompatibility in the given concentration range. Our results clearly suggest that the synthetic Gd-Au DENPs are amenable for dual-modality MR/CT imaging of breast cancer cells.
\end{abstract}

Keywords: PAMAM dendrimers, gold nanoparticles, gadolinium, PEGylation, CT imaging, MR imaging, breast cancer cells

\section{Introduction}

Over the past decade, molecular imaging (MI) has provided the possibility of obtaining in vitro and in vivo physiological and pathological information with high sensitivity and specificity. ${ }^{1}$ The modalities of MI include optical imaging, ${ }^{2}$ computed tomography (CT) imaging, ${ }^{3}$ magnetic resonance (MR) imaging, ${ }^{4}$ position emission tomography, ${ }^{5}$ and single photon emission computed tomography. ${ }^{6}$ As two of the important $\mathrm{MI}$ technologies, CT and MR afford better resolution than other imaging modalities. They will have more advantages when appropriate MI probes are used.

Recent advances in nanotechnology show that multifunctional nanomaterials can be used as MI probes, which are able to not only carry targeting molecules and drugs to perform targeted diagnosis and therapeutics, ${ }^{7}$ but also afford different imaging modalities dependent on the composition of the materials. ${ }^{8}$ For accurate and selfconfirming cancer diagnosis, it is essential to combine dual-mode and multi-mode imaging functionalities within one nanoparticle (NP) system, which can avoid putting additional stress on the body's blood clearance capability via administration of multiple doses of agents. ${ }^{8}$ submit your manuscript $\mid$ www.dovepress.com

Dovepress

http://dx.doi.org// 0.2147/IJN.S46177 
Due to the limitations of the clinically used CT contrast agents, such as short imaging time, renal toxicity at relatively high concentrations, and nonspecificity, NP-based inorganic agents have been developed. For example, gold NPs $(\text { AuNPs })^{3,9}$ with a high X-ray absorption coefficient, have been used as CT contrast agents due to their satisfactory biocompatibility after surface functionalization, long blood circulation time, and easy biofunctionalization on the surface. On the other hand, gadolinium (Gd)-based $\mathrm{T}_{1}$ contrast agents, which are now widely used as MR contrast agents for clinical diagnosis, also have some shortcomings, such as low $\mathrm{T}_{1}$ relaxivity, short blood half-life, and the instability of Gd(III)/ diethylenetriaminepentaacetic acid (DTPA) complexes that can cause nephrogenic systemic fibrosis. ${ }^{10,11}$ Consequently, macromolecular MR contrast agents have been developed. These macromolecular agents have promising features, such as well-defined structure, desirable pharmacokinetics, and high in vivo $T_{1}$ relaxivity. ${ }^{12,13}$ However, very few contrast agents have been developed that provide multiple imaging contrast effects (ie, effective for both MR and $\mathrm{CT}$ imaging). These multimodal imaging probes, such as iohexol-gadoteridol, ${ }^{14}$ Gd-G8 dendrimer, ${ }^{15}$ Gd-chelated AuNPs,,${ }^{16,17}$ and FePt NPs, ${ }^{18}$ have offered somewhat limited sensitivity, stability, or blood circulation time. Therefore, the preparation of a dual-modality contrast agent that is stable while permitting sensitive imaging with both MR and CT still remains a great challenge.

The surface of the poly(amidoamine) (PAMAM) dendrimers can be modified with different peripheral functional groups that allow them to be used in various biomedical applications, such as conjugating chelating agents for MR contrast agents ${ }^{19}$ or for the delivery of drugs and nucleic acids..$^{20,21}$ Additionally, the interior features of the dendrimers enable them to be used as templates or stabilizers for preparation of inorganic NPs, ${ }^{22}$ such as gold and silver. Our previous studies ${ }^{3,23-25}$ have shown that the generation 5 (G5) PAMAM dendrimer-entrapped gold nanoparticles (Au DENPs) can be used as blood pool CT contrast agents or targeted cancer-specific CT agents. In a very recent study, ${ }^{26}$ we have shown that Gd-loaded Au DENPs (Gd-Au DENPs) prepared using the facile dendrimer chemistry enable MR/CT dual-mode imaging of the heart, liver, kidney, and bladder of rat or mouse within a time frame of 45 minutes. Our prior successes lead us to hypothesize that the synthesized multifunctional Gd-Au DENPs may also be used for dualmode MR/CT imaging of tumors.

In this study, following the protocols reported in our previous work, ${ }^{26}$ multifunctional Gd-Au DENPs were synthesized and characterized for dual-mode MR/CT imaging of breast cancer cells in vitro and in vivo. The cytotoxicity of the multifunctional Gd-Au DENPs was evaluated via 3-(4,5-dimethylthiazol-2-yl)-2,5-diphenyltetrazolium bromide (MTT) cell viability assay and flow cytometry. The cellular particles taken up were confirmed via transmission electron microscopy (TEM) imaging. Finally, the Gd-Au DENPs were used for dual-mode MR/CT imaging of MCF-7 cells in vitro and xenografted tumor model in vivo.

\section{Materials and methods Characterization techniques}

The multifunctional Au-DENPs were synthesized and characterized according to our previous protocol. ${ }^{26} \mathrm{~A}$ Lambda $25 \mathrm{UV} /$ Vis spectrometer (PerkinElmer, Waltham, MA, USA) was used to collect ultraviolet and visible (UV-Vis) spectra. A JEOL 2010F analytical electron microscope (JEOL, Tokyo, Japan) was used to characterize the size and morphology of the Gd-Au DENPs.

\section{Cell culture}

MCF-7 breast cancer cells were continuously cultured in RPMI 1640 medium with 10\% Fetal Bovine Serum (FBS) at $37^{\circ} \mathrm{C}$ and $5 \% \mathrm{CO}_{2}$.

\section{Cytotoxicity of Gd-Au DENPs}

The cytotoxicity of Gd-Au DENPs was conducted according to a previously reported method. ${ }^{23,27}$ The morphology of the cells after treatment with the Gd-Au DENPs was observed with optical microscopy (Nikon, Tokyo, Japan) after staining with hematoxylin and eosin (HE). The viability of cells treated with the Gd-Au DENPs was evaluated using an MTT assay. Varying concentrations of Gd-Au DENPs $([\mathrm{Au}]=5-50 \mu \mathrm{M})$ was added into the MCF-7 cell culturing medium. The toxicity of the Gd-Au DENPs was further examined by the flow cytometric detection of cell cycles and apoptosis. MCF-7 cells were cultured with fresh medium containing different concentrations of the Gd-Au DENPs $([\mathrm{Au}]=25$ and $50 \mu \mathrm{M})$.

\section{Cellular uptake of the Gd-Au DENPs}

Cellular uptake of the Gd-Au DENPs was observed by using an H600 transmission electron microscope (TEM), (Hitachi, Tokyo, Japan) operating at a voltage of $60 \mathrm{kV}$. MCF-7 cells were plated in 6-well cell culture plates at a density of $3 \times 10^{5}$ cells per well in RPMI 1640 medium with $10 \%$ FBS for 24 hours to grow to approximately $80 \%$ confluence. Then the Gd-Au DENPs were added to each 
well with a final $\mathrm{Au}$ concentration of $50 \mu \mathrm{M}$ and incubated for 24 hours at $37^{\circ} \mathrm{C}$.

\section{In vitro MR/CT imaging of breast cancer cells}

For dual-mode MR/CT imaging, MCF-7 cells were incubated with $\mathrm{Gd}-\mathrm{Au}$ DENPs at different $\mathrm{Au}$ concentrations $(0-50 \mu \mathrm{M})$ for 4 hours at $37^{\circ} \mathrm{C}$. After washing three times with phosphate buffered saline (PBS), the cells were trypsinized, centrifuged, and resuspended with $100 \mu \mathrm{L}$ of PBS in a $0.5 \mathrm{~mL}$ Eppendorf tube (Eppendorf, Hamburg, Germany) that contained approximately $1.5 \times 10^{6}$ cells in each tube. The $\mathrm{T}_{1}$ relaxation rate for each sample was measured using a 3.0 T Signa HDxt superconducting MR system (GE Medical Systems, Milwaukee, WI, USA) with a wrist receiver coil and a fast spin-echo sequence (repetition time [TR]/echo time $[\mathrm{TE}]=2000 / 81.9 \mathrm{~ms}$, matrix $=256 \times 256$, section thickness $=2 \mathrm{~mm}$, and field of view $[\mathrm{FOV}]=80 \times 80 \mathrm{~mm}$ ). Regions of interest were selected to encompass crosssections of respective tubes. The mean $\mathrm{T}_{1}$ weighted signal intensity was measured for each cell sample $\left(\mathrm{S}_{\text {mean }}\right)$. Separate regions of interest were drawn outside the tube to estimate relative noise levels based upon the standard deviation of the background signal (NSD). Then the relative signal-to-noise ratio ( $\mathrm{SNR}=\mathrm{S}_{\text {mean }} / \mathrm{NSD}$ ) were calculated. For tumor-bearing mice (see below), these SNR measurements were repeated for each MR scan before or after injection.

For CT imaging, the cell suspension in each tube was placed in a self-designed scanning holder and then scanned using a volume computed tomography (VCT) imaging system (GE LightSpeed, GE Medical Systems, Milwaukee, WI, USA), operating at $80 \mathrm{~mA}, 100 \mathrm{kV}$ with 0.625 -mm thickness.

\section{In vivo $M R / C T$ imaging}

Animal experiments and animal care were conducted according to protocols approved by the institutional committee. Male 4-week-old BALB/c nude mice ( $\mathrm{n}=9$, Slac Laboratory Animal Center, Shanghai, People's Republic of China) were subcutaneously injected with $1 \times 10^{6}$ cells/mouse in the right second mammary fat pad. When the tumor nodules reached a volume of $0.1-1 \mathrm{~cm}^{3}$, approximately 3 weeks after injection, the mice were anesthetized with an intraperitoneal injection of $0.3 \mathrm{~mL}$ of $3 \%$ pentobarbital sodium $(12 \mathrm{~mL} / \mathrm{kg})$, and $200 \mu \mathrm{L}$ of Gd-Au DENPs $([\mathrm{Au}]=50 \mathrm{mM}$, $[\mathrm{Gd}]=5.34 \mathrm{mM})$ was delivered via the tail vein. MR scans were performed before injection and 30 minutes, 120 minutes, 180 minutes, 12 hours and 24 hours after injection of the particles. A 3.0 T Signa HDxt superconducting clinical MR system (GE Medical
Systems) was used with a custom-built rodent receiver coil (Chenguang Med Tech, Shanghai, People's Republic of China). At each time point for each animal, 2D spin-echo MR images were obtained with a 2-mm slice thickness, TR/TE $2000 / 81.9 \mathrm{~ms}$, a $6 \times 6 \mathrm{~cm} \mathrm{FOV}$, and a $256 \times 160$ matrix. The MR images were processed using the strategy described above for in vitro MR studies.

For CT imaging of the tumor model, the scans were performed before and 15 minutes, 100 minutes, 160 minutes, 12 hours, and 24 hours after injection of the particles using a GE LightSpeed VCT clinical imaging system (GE Medical Systems) with a $100 \mathrm{kV}$ tube voltage, an electrical current of $80 \mathrm{~mA}$, and a slice thickness of $0.625 \mathrm{~mm}$.

\section{In vivo biodistribution of Gd-Au DENPs}

After MR and CT imaging of the tumor model at the different time points after injection of the Gd-Au DENPs $([\mathrm{Au}]=50 \mathrm{mM})$, the mice were euthanized. The liver, spleen, heart, blood, kidney, and tumors of the mice were extracted and weighed. The organs were cut into small pieces and incubated in aqua regia solution overnight. The Au content was determined using a Leeman Prodigy inductively coupled plasma atomic emission spectroscopy (ICP-AES, Teledyne Leeman Labs, Hudson, NH, USA).

\section{Statistical analysis}

The significance of the experimental data were evaluated by one-way ANOVA statistical analysis. The significance level was set as 0.05 .

\section{Results and discussion Synthesis and characterization of Gd-Au DENPs}

Similar to our previous study, ${ }^{26}$ amine-terminated G5 PAMAM dendrimers were multifunctionalized through grafting gadolinium chelator DOTA-NHS and carboxylic acid functionalized methoxyl polyethylene glycol onto their surface. Using functional G5 dendrimers as templates, $\mathrm{Au}$ DENPs were prepared with sodium borohydride reduction chemistry. After chelating Gd(III) ions with the attached DOTA moieties onto the dendrimer surface, the remaining dendrimer terminal amine groups were acetylated to neutralize the positive charges. The obtained multifunctional $\mathrm{Gd}-\mathrm{Au}$ DENPs were used for both MR and CT imaging of cancer cells in this study. Detailed characterization of the $\mathrm{Gd}-\mathrm{Au}$ DENPs can be seen in our previous study ${ }^{26}$ and in the supporting information. Figure 1 shows the UV-Vis spectrum of the Gd-Au DENPs. The surface plasma resonance peak 


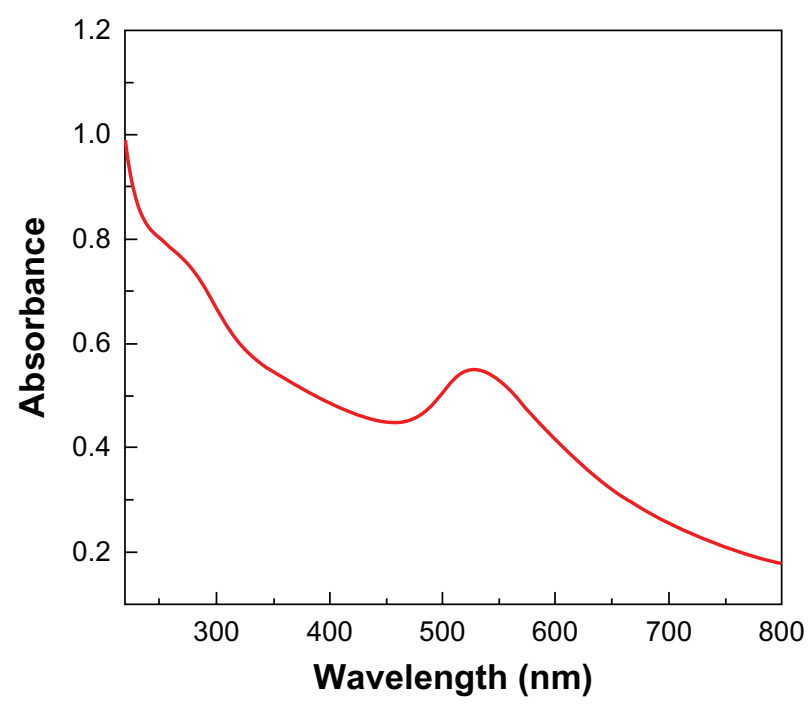

Figure I UV-Vis spectrum of Gd-Au DENPs.

Abbreviations: Gd-Au DENP, dendrimer-entrapped gold nanoparticle; UV-Vis, ultraviolet and visible spectrum.

located at $520 \mathrm{~nm}$ clearly indicates the formation of AuNPs. In addition, the size and morphology of the Gd-Au DENPs were characterized with TEM (Figure 2). It can be seen that the Gd-Au DENPs have a spherical shape and a uniform size distribution. The diameter of the Gd-Au DENPs was estimated to be $4.3 \mathrm{~nm}$. Similar to our previous study, ${ }^{26}$ with the coexistence of two radiodense imaging elements of Gd(III) ions and AuNPs within one NP system, the formed Gd-Au DENPs display both $\mathrm{T}_{1}$ relaxivity (for $\mathrm{T}_{1}$ MR imaging mode) and X-ray attenuation property (for CT imaging mode), which enables MR/CT dual-mode imaging applications.

\section{Cytotoxicity of Gd-Au DENPs}

Before using the Gd-Au DENPs for MR and CT dualmodality molecular imaging of the model breast cancer cell line, their cytocompatibility was explored. In general, the cytotoxicity of amine-terminated G5 PAMAM dendrimers arises from the strong electrostatic interaction between the positively charged dendrimers and the negatively charged cell membranes. ${ }^{28}$ Therefore, it is crucial to neutralize the positive charges of the formed Gd-Au DENPs via a final acetylation step. MCF-7 cells were used to test the cytotoxicity of the Gd-Au DENPs by MTT cell viability assay, cell morphology observation, and flow cytometric analysis of the cell cycles and apoptosis.

MTT assay was performed to evaluate the cell viability by incubation of the MCF-7 cells with Gd-Au DENPs at 0 , $5,10,25$, and $50 \mu \mathrm{M}$ concentrations for 24 hours (Figure 3 ). The viability of the cells treated with Gd-Au DENPs did not exhibit any significant differences compared with the cells treated with PBS buffer $(P>0.05)$. The nontoxicity of the Gd-Au DENPs at $50 \mu \mathrm{M}$ concentration may be due to the acetylation and PEGylation modification of the dendrimer surface. This is very important for their biomedical imaging applications, particularly under circumstances that require the particle concentration to be sufficiently high for in vivo detection.

The morphology of the HE-stained MCF-7 cells before and after incubation with the Gd-Au DENPs was observed using optical microscopy (Figure 4). It is clear that morphology of the cells incubated with different concentrations of Gd-Au DENPs did not display any apparent changes compared to the control cells treated with PBS buffer. These results indicate that the Gd-Au DENPs did not impact of the morphology of the MCF-7 cells, in agreement with our previous report related to PEGylated Au DENPs. ${ }^{23}$

Flow cytometry was used to further investigate the influence of the Gd-Au DENPs on the cell cycle and
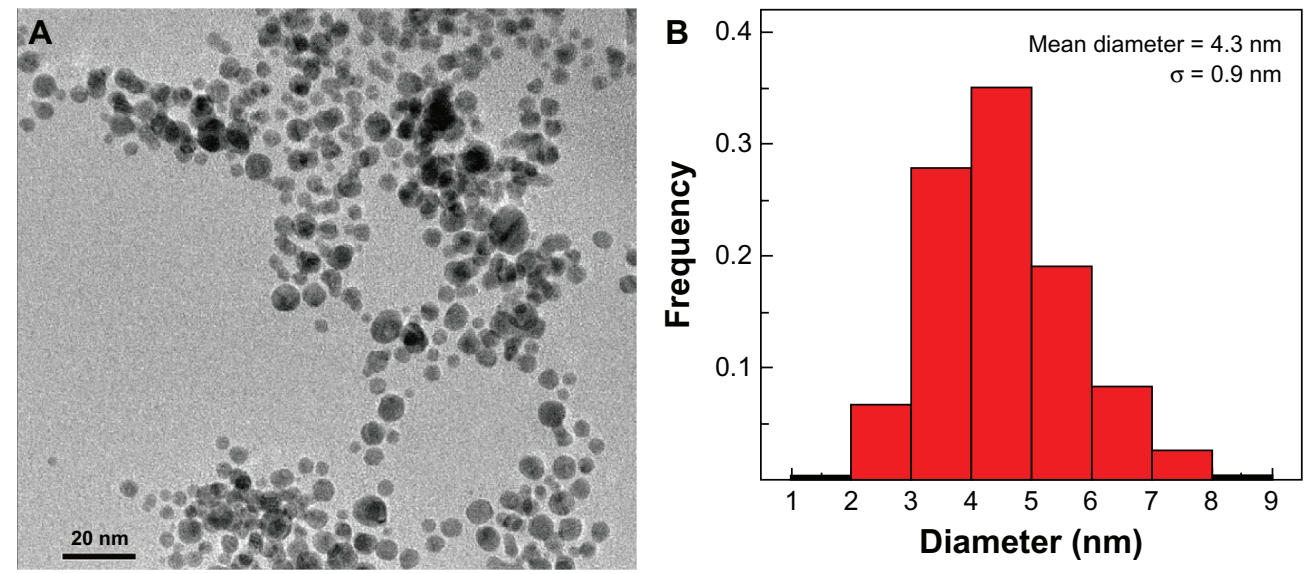

Figure 2 TEM image and size distribution histogram of Gd-Au DENPs.

Abbreviations: Gd-Au DENP, dendrimer-entrapped gold nanoparticle; TEM, transmission electron microscopy. 


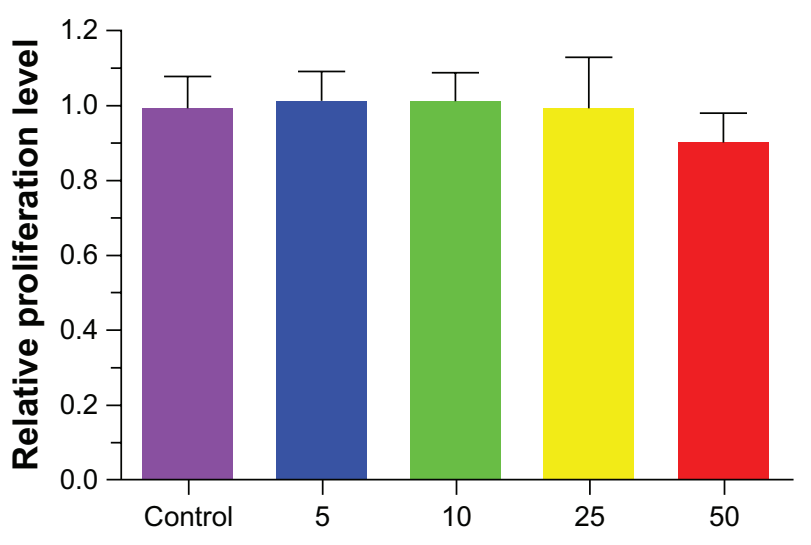

[Au] concentrations $(\mu \mathrm{M})$

Figure 3 MTT assay of MCF-7 cell viability after treatment with Gd-Au DENPs at the gold concentration of $0-50 \mu \mathrm{M}$ for 24 hours.

Note: MCF-7 cells treated with PBS buffer were used as a control.

Abbreviations: Au, gold; Gd-Au DENP, dendrimer-entrapped gold nanoparticle; MTT, 3-(4,5-dimethylthiazol-2-yl)-2,5-diphenyltetrazolium bromide; PBS, phosphate buffered saline.

apoptosis (Table 1 and Figure $\mathrm{S} 3$ ). The sub- $\mathrm{G}_{1}$ fraction of the MCF-7 cells incubated with the Gd-Au DENPs at Au concentrations of $25 \mu \mathrm{M}$ and $50 \mu \mathrm{M}$ were determined to be $2.39 \pm 0.25 \%$ and $2.46 \pm 0.47 \%$, respectively. Compared with the negative control cells treated with PBS buffer $(2.24 \pm 0.12 \%)$, there was no statistical difference. This result demonstrates that the Gd-Au DENPs have no effect on the cell cycle of the MCF-7 cells.

In brief, the combined MTT assay of cell viability, the observation of cell morphology, and the flow cytometric analysis of the cell cycles and apoptosis clearly indicate that the Gd-Au DENPs are noncytotoxic in the given concentration range, which is essential for their MR/CT dual-modality imaging applications.

\section{In vitro cellular uptake of Gd-Au DENPs}

For efficient imaging of cancer cells, it is important to explore the ability of the particles to be taken up by the cells. MCF-7 cells treated with the Gd-Au DENPs were examined using TEM to identify the distribution of the particles in the subcellular compartments. In the TEM images (Figure 5), numerous high electron-staining particles can be observed in the cytoplasm of the MCF-7 cells, particularly in the lysosomes of the cell after incubation with the Gd-Au DENPs for 24 hours. This result confirmed that the Gd-Au DENPs were internalized by the cell rather than adhering to the surface of the cells. The internalization of the Gd-Au DENPs potentially occurs through two distinct mechanisms, phagocytosis and diffusion via cell walls, in agreement with the literature. ${ }^{29,30}$ Furthermore, the TEM data also revealed that the incubation of the Gd-Au DENPs with an Au concentration as high as $50 \mu \mathrm{M}$ did not markedly affect the cell morphology, corroborating with the MTT assay and optical microscopy observation data.

\section{MR/CT dual-modality imaging of breast cancer cells in vitro}

To prove our hypothesis that the developed Gd-Au DENPs are able to be used as MR/CT dual-modality contrast agents for cancer cell imaging, the suspensions of MCF-7 cells incubated with $\mathrm{Gd}-\mathrm{Au}$ DENPs at different $\mathrm{Au}$ concentrations $(0 \mu \mathrm{M}, 5 \mu \mathrm{M}, 10 \mu \mathrm{M}, 25 \mu \mathrm{M}$, and $50 \mu \mathrm{M}$, respectively) were imaged using clinical MR and CT imaging systems. Figures 6 and 7 present transverse MR images and the sagittal CT images of MCF-7 cells with or without incubation with the Gd-Au DENPs. MCF-7 cell suspensions incubated with increasing concentrations of Gd-Au DENPs displayed increased contrast enhancement when compared to control cells treated with PBS buffer. Both the $\mathrm{T}_{1}$-weighted MR images (Figure 6A) and the $\mathrm{CT}$ images (Figure 7A) of cells incubated with Gd-Au DENPs at high Au concentrations $(25 \mu \mathrm{M}$ and $50 \mu \mathrm{M})$ were much brighter than those of the cells incubated with Gd-Au DENPs at low concentrations ( $5 \mu \mathrm{M}$ and $10 \mu \mathrm{M})$ and those of the negative control cells treated with PBS buffer.

A quantitative analysis of the MR images (Figure 6B) further revealed that the $\mathrm{T}_{1}$-weighted SNR of MCF-7 cells incubated with the Gd-Au DENPs at the Au concentration
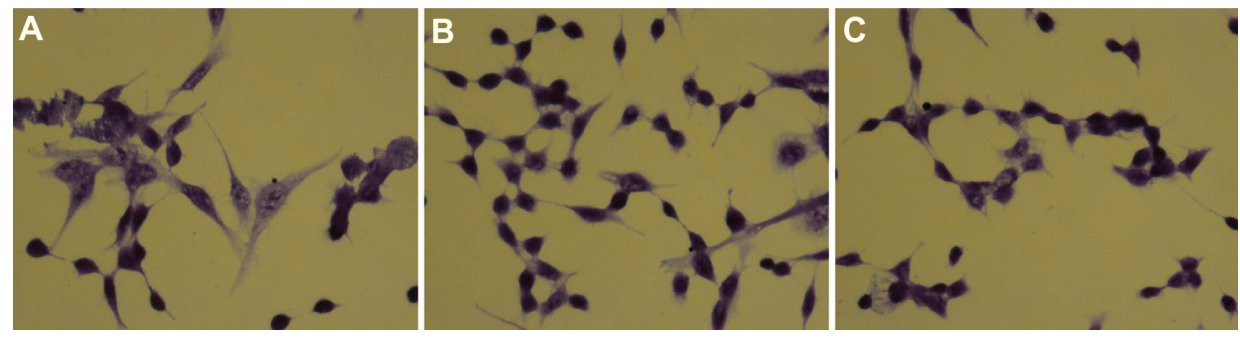

Figure 4 The morphology of MCF-7 cells treated with PBS buffer (A) and Gd-Au DENPs at the Au concentrations of $25 \mu \mathrm{M}$ (B) and $50 \mu \mathrm{M}$ (C) for 24 hours. Abbreviations: Au, gold; Gd-Au DENP, dendrimer-entrapped gold nanoparticle; PBS, phosphate buffered saline. 
Table I Apoptosis and cell cycle analysis of MCF-7 cells after incubation with the Gd-Au DENPs for 4 hours (mean \pm SD, $n=4$ )

\begin{tabular}{|c|c|c|c|c|c|}
\hline \multirow[t]{2}{*}{ Group } & \multirow[t]{2}{*}{ Apoptosis (\%) } & \multicolumn{4}{|c|}{ Cell cycle (\%) } \\
\hline & & $\mathbf{G}_{0}-\mathbf{G}_{1}$ & $\mathbf{G}_{2}-\mathbf{M}$ & $\mathbf{S}$ & $\mathbf{G}_{2} / \mathbf{G}_{1}$ \\
\hline Control & $2.24 \pm 0.12$ & $51.73 \pm 0.32$ & $1.33 \pm 0.06$ & $47.15 \pm 0.32$ & $2.13 \pm 0.01$ \\
\hline $25 \mu \mathrm{M}(\mathrm{Au})$ & $2.39 \pm 0.25$ & $51.94 \pm 0.58$ & $1.58 \pm 0.15$ & $46.46 \pm 0.48$ & $2.24 \pm 0.02$ \\
\hline $50 \mu \mathrm{M}(\mathrm{Au})$ & $2.46 \pm 0.47$ & $51.29 \pm 0.56$ & $1.28 \pm 0.19$ & $47.62 \pm 0.49$ & $2.16 \pm 0.01$ \\
\hline
\end{tabular}

Abbreviations: Au, gold; G, gap; Gd-Au DENP, dendrimer-entrapped gold nanoparticle; M, metaphase; S, synthesis; SD, standard deviation.

of $50 \mu \mathrm{M}$ was significantly greater than those of the cells incubated with Gd-Au DENPs at lower concentrations $(5 \mu \mathrm{M}$, $10 \mu \mathrm{M}$, and $25 \mu \mathrm{M}$, respectively) and that of the negative control cells $(P<0.05)$. Likewise, a quantitative analysis of the CT values of these cell samples (Figure 7B) revealed the same trend of increased CT value with the Au concentration of the particles. The brighter MR and CT images (higher $\mathrm{T}_{1}$ SNR and CT values) of cell samples should be associated with greater cellular uptake of the particles at a higher concentration of Gd-Au DENPs. Overall, the in vitro cell imaging experiments demonstrate that the Gd-Au DENPs are able to be used as a positive contrast agent for both MR and CT imaging of cancer cells.

\section{MR/CT dual-modality imaging of MCF-7 xenograft tumor model}

The excellent in vitro MR/CT imaging performance of the Gd-Au DENPs along with the good biocompatibility of the NPs motivated us to pursue their applicability for in vivo $\mathrm{MR} / \mathrm{CT}$ imaging of the xenotransplanted tumor model. For MR imaging, MCF-7 tumor-bearing BALB/c nude mice were administered $200 \mu \mathrm{L}$ Gd-Au DENPs ([Gd] $=5.34 \mathrm{mM}$, $[\mathrm{Au}]=50 \mathrm{mM}$ ) via the tail vein. $\mathrm{MR}$ images (Figure $8 \mathrm{~A}$ ) were obtained both before administration and 30 minutes,
120 minutes, 180 minutes, 12 hours, and 24 hours after administration of the Gd-Au DENPs using a clinically relevant field strength of 3 tesla (T) MR system. It is clear that the tumor site exhibits an obvious enhancement with a significantly higher $\mathrm{T}_{1}$-weighted $\mathrm{SNR}$ after administration of the Gd-Au DENPs compared with those before injection. Quantitative analysis of the MR $\mathrm{T}_{1}$-weighted $\mathrm{SNR}$ values of the tumor area at different time points revealed that the tumor area had a higher SNR value at 120 minutes after injection. At the time point of 24 hours after injection, the $\mathrm{T}_{1}$-weighted $\mathrm{SNR}$ value of the tumor area was still much higher than that of the tumor area before injection (Figure 8B).

For CT imaging, after the same dose of Gd-Au DENPs was intravenously injected via the tail vein, CT scans were performed at 15 minutes, 100 minutes, 160 minutes, 12 hours, and 24 hours after injection using a clinical CT imaging system. Figure 9 shows the tumor CT images before and after injection of the Gd-Au DENPs. The tumor site has obvious enhancement, with significantly brighter images, after administration of the Gd-Au DENPs compared with the images before the injection (Figure 9A). Quantitative analysis of the CT value of the tumor area at different time points showed that the tumor area had the highest CT value
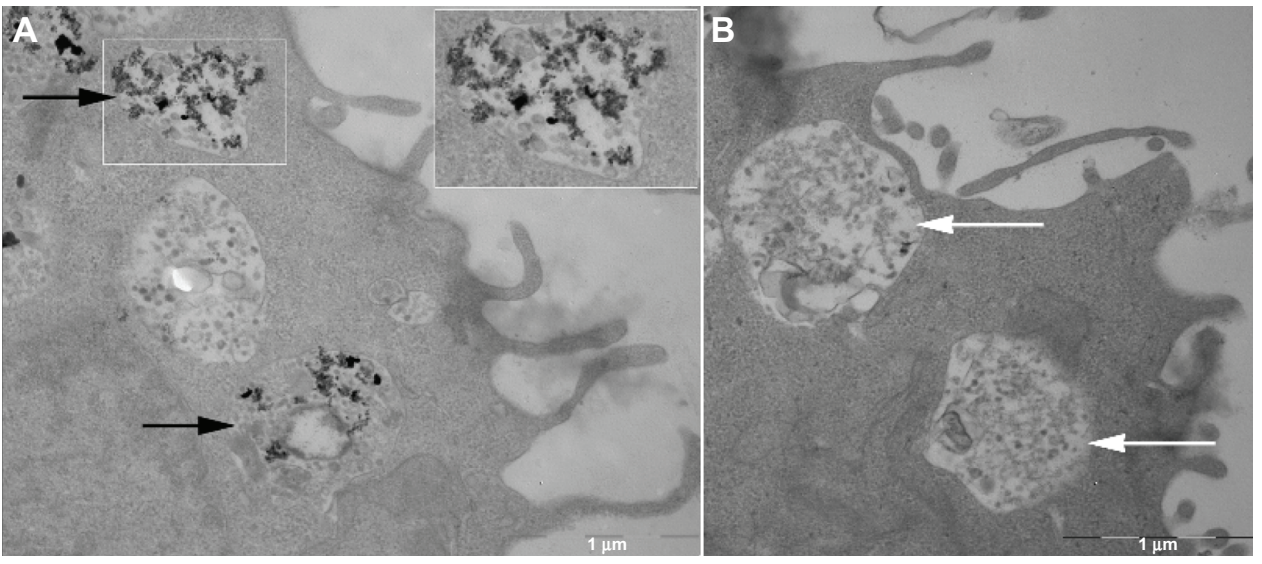

Figure 5 TEM images of the MCF-7 cells incubated with Gd-Au DENPs at a concentration of $50 \mu$ M for 24 hours $(\mathbf{A})$ and the negative control cells without treatment (B). Notes: Gd-Au DENPs were taken up by endosomes as electron-dense nanoparticles, indicated by black arrows; the white arrows show the normal endosome without Gd-Au DENPs.

Abbreviations: Gd-Au DENP, dendrimer-entrapped gold nanoparticle; TEM, transmission electron microscopy. 


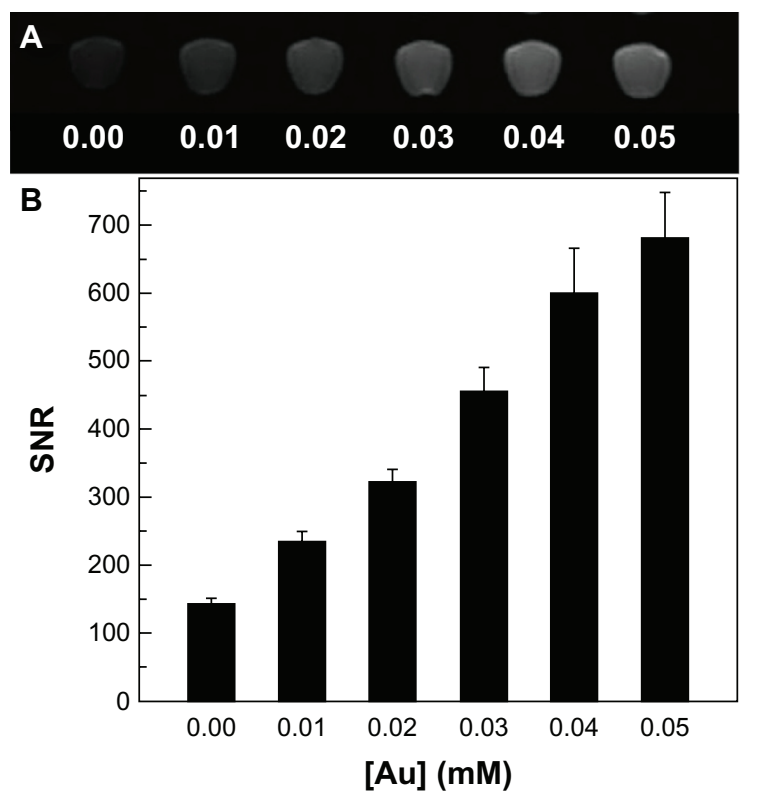

Figure 6 Transverse MR images (A) and MR SNR values (B) of the MCF-7 cells treated with Gd-Au DENPs at different concentrations for 4 hours $(n=3)$.

Abbreviations: Au, gold; Gd-Au DENP, dendrimer-entrapped gold nanoparticle; $M R$, magnetic resonance; SNR, signal-to-noise ratio.

at 100 minutes after injection, and at 24 hours after injection, the CT value of the tumor area was still much higher than it was before injection (Figure 9B). The CT imaging results are in accordance with the MR imaging data, although the imaging time points are not exactly the same.
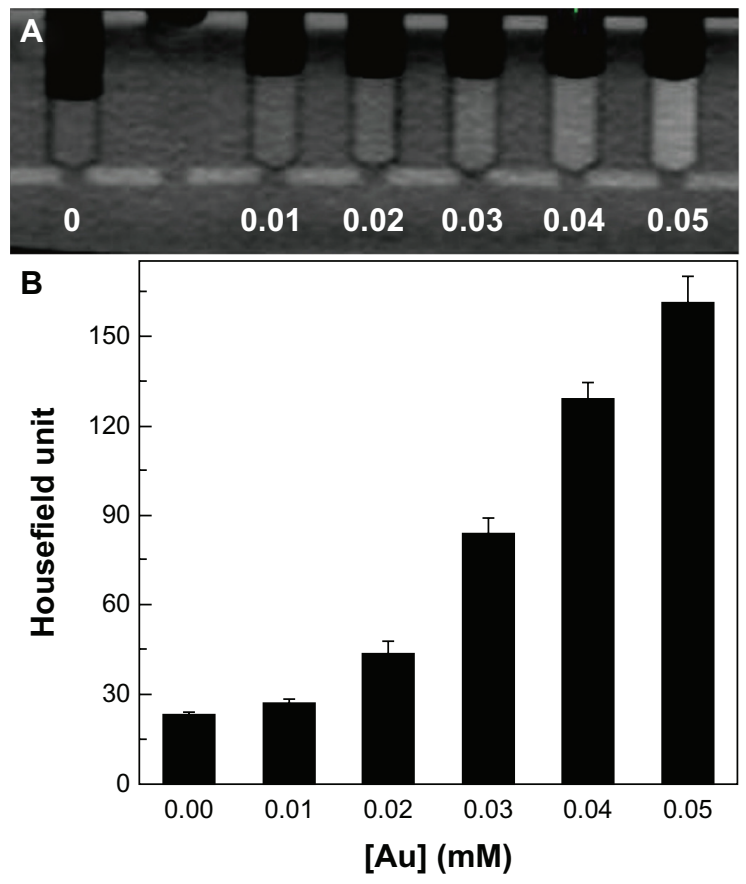

Figure 7 Sagittal CT images (A) and CT values (B) of the MCF-7 cells treated with Gd-Au DENPs at different concentrations for 4 hours $(n=3)$.

Abbreviations: Au, gold; CT, computed tomography; Gd-Au DENP, dendrimerentrapped gold nanoparticle; SNR, signal-to-noise ratio.
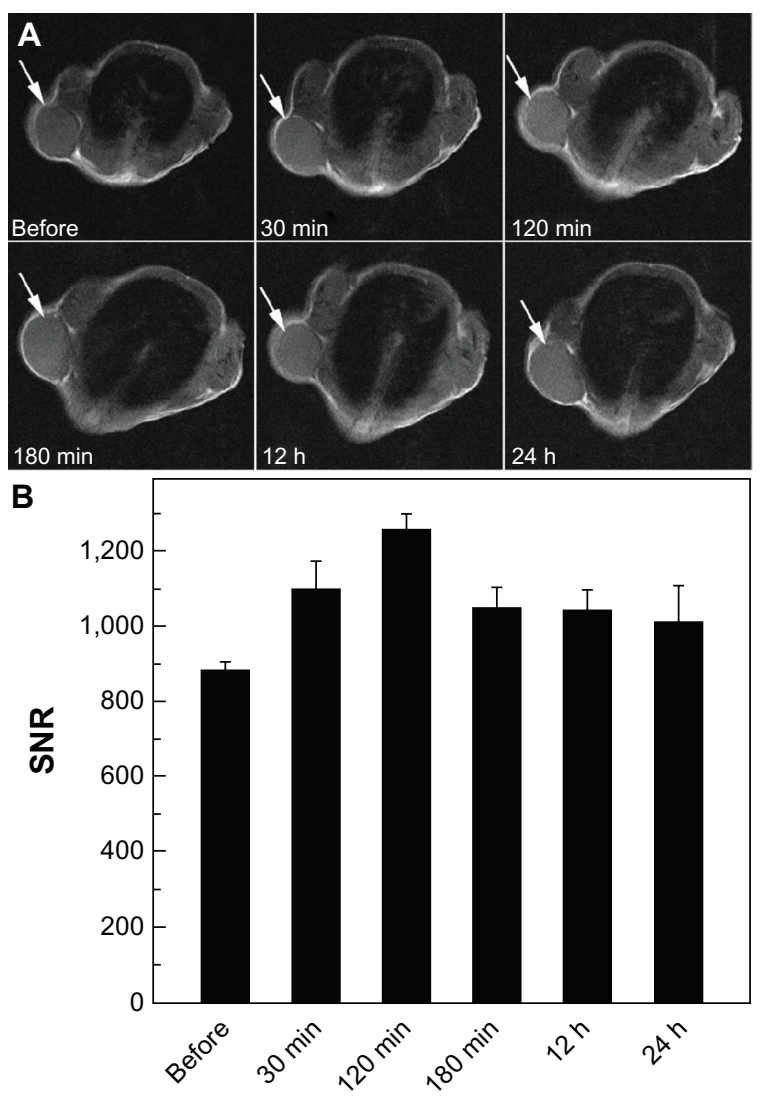

Figure 8 Representative transverse MR images (A) and MR SNR values (B) of the MCF-7 tumor xenografts in nude mice before and after intravenous injection with Gd-Au DENPs for 30 minutes, 120 minutes, 180 minutes, 12 hours, and 24 hours, respectively.

Note: The white arrows in $(\mathbf{A})$ indicate the location of the tumor.

Abbreviations: Gd-Au DENP, dendrimer-entrapped gold nanoparticle; h, hours; min, minutes; MR, magnetic resonance; SNR, signal-to-noise ratio.

The efficient MR/CT imaging of the MCF-7 tumor model suggests that the developed Gd-Au DENPs demonstrate prolonged blood circulation time, which may be partly due to the modification of PEG moieties on the surface of dendrimers, similar to our previous study. ${ }^{23}$ With the prolonged blood circulation time, part of the Gd-Au DENPs could be transported to the tumor site via the enhanced permeability and retention (EPR) effect, ${ }^{31-34}$ thereby allowing for effective $\mathrm{MR} / \mathrm{CT}$ imaging of tumors. This is very important for the early stage diagnosis of unknown tumors. Our results confirm that the developed Gd-Au DENPs can be used as a dual-mode contrast agent for MR/CT imaging of tumors in vivo. In addition, the xenografted MCF-7 tumors were confirmed by gross specimen (Figure S4A and B) and HE staining (Figure S4C), which showed the features of the MCF-7 cells.

\section{In vivo biodistribution of Gd-Au DENPs}

The tumor uptake and the biodistribution of the Gd-Au DENPs were investigated at 1 hour, 4 hours, 12 hours, and 


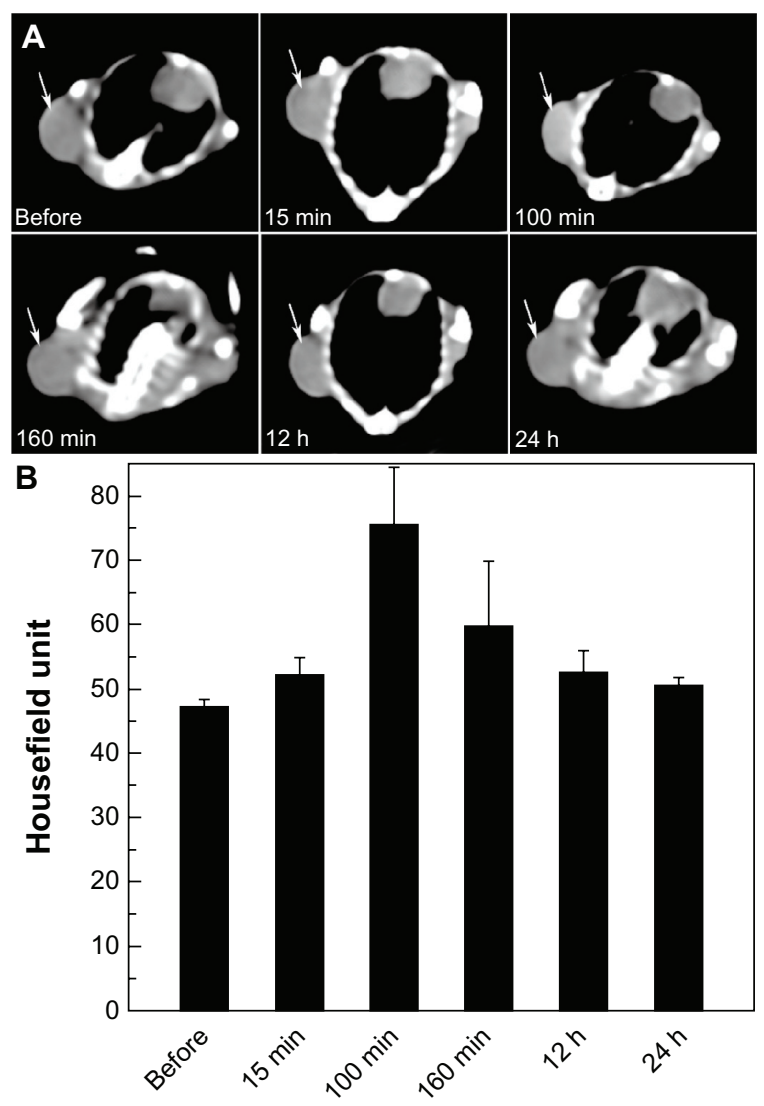

Figure 9 Representative transverse CT images (A) and CT values (B) of the MCF-7 tumor xenografts in nude mice before and after intravenous injection with Gd-Au DENPs for 15 minutes, 100 minutes, 160 minutes, 12 hours, and 24 hours, respectively. Note: The white arrows in $(\mathbf{A})$ indicate the location of the tumor.

Abbreviations: CT, computed tomography; Gd-Au DENP, dendrimer-entrapped gold nanoparticle; $h$, hours; min, minutes; SNR, signal-to-noise ratio.

24 hours after intravenous administration. ICP-AES was performed to analyze the Au concentration in the tumor and several major organs, including the heart, lung, spleen, liver, kidney, and blood (Figure 10). The lung showed the most significant Au uptake $(0.943 \mathrm{~g} / \mathrm{kg} \pm 0.223 \mathrm{~g} / \mathrm{kg})$ at the 4-hour time point, whereas the spleen showed the most significant $\mathrm{Au}$ uptake $(0.742 \mathrm{~g} / \mathrm{kg} \pm 0.198 \mathrm{~g} / \mathrm{kg})$ at the 24 -hour time point, which is similar to results from our previous studies. ${ }^{23,26}$ These results suggest that the multifunctional NPs are able to pass the lung first from the inferior vena cava and the right heart, and some NPs are most likely held back by the pulmonary capillary network. The lower uptake of $\mathrm{Au}$ in both the liver and kidney suggests that the Gd-Au DENPs are able to escape the reticuloenthelial system located in the liver and pass through the renal filter, consequently allowing for an efficient transport of the particles to the tumor region via the passive EPR effect. In this study, the Au uptake in the tumor region was measured to be up to $0.276 \mathrm{~g} / \mathrm{kg} \pm 0.006 \mathrm{~g} / \mathrm{kg}$ at

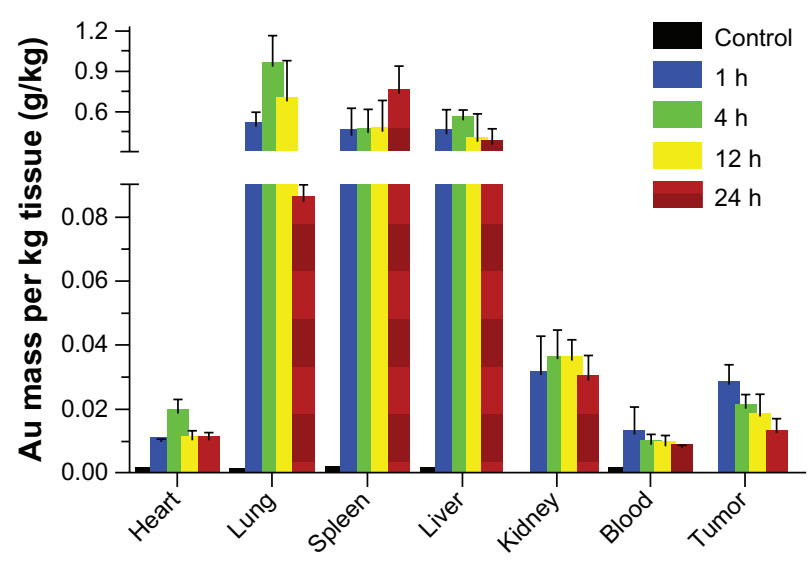

Figure 10 The biodistribution of Gd-Au DENPs in different organs and the MCF-7 tumor xenograft.

Note: The data were obtained by ICP-AES at the indicated time after injection in the MCF-7-xenografted BALB/c nude mice models.

Abbreviations: Au, gold; Gd-Au DENP, dendrimer-entrapped gold nanoparticle; $h$, hours; ICP-AES, inductively coupled plasma atomic emission spectroscopy.

1 hour after intravenous injection, which enabled effective $\mathrm{MR} / \mathrm{CT}$ imaging of the tumors. The biodistribution of the Gd-Au DENPs in blood further confirmed their long blood circulation time. At 1 hour after injection, the biodistribution of the NPs in blood was measured to be $0.0124 \mathrm{~g} / \mathrm{kg} \pm 0.008 \mathrm{~g} / \mathrm{kg}$, and the particle concentration was estimated to be $0.0080 \mathrm{~g} / \mathrm{kg} \pm 0.0008 \mathrm{~g} / \mathrm{kg}$ at 24 hours after administration. The prolonged blood circulation time is likely due to the modification of PEG moieties on the dendrimer surface, effectively avoiding the nonspecific uptake by the reticuloenthelial system. ${ }^{35}$ Detailed pharmacokinetic studies of the Gd-Au DENPs at extended time periods are still necessary for a thorough understanding of the biodistribution of the NPs.

\section{Conclusion}

Multifunctional Gd(III)-loaded Au DENPs were effectively used as a dual-modality contrast agent for MR/CT molecular imaging of breast cancer cells in vitro and in vivo. MTT assay of cell viability, cell morphology observation, and the flow cytometry analysis of the cell cycles and apoptosis reveal that the Gd-Au DENPs are noncytotoxic in a concentration range of $0-50 \mu \mathrm{M}$. The efficient cellular uptake of the Gd-Au DENPs as verified by TEM enables dual-mode MR/CT imaging of breast cancer cells (MCF-7 cells) in vitro after incubation of the particles and the xenograft tumor model in vivo after intravenous injection of the particles. The developed Gd-Au DENPs are expected to be used as a multifunctional nanoplatform for MR/CT molecular imaging of different types of cancer. 


\section{Acknowledgments}

This research is financially supported by the National Natural Science Foundation of China $(21273032,81101150)$, the Shanghai Natural Science Foundation (11ZR142930012ZR1447700), the Medical Guiding Program of Shanghai Science and Technology Committee (114119a0800, 20124Y075), the Shanghai Songjiang Medical Climbing Program (2011PD04), and the Fund of the Science and Technology Commission of Shanghai Municipality (11 nm0506400 for XS, and $11 \mathrm{JC} 1410500 \mathrm{GZ}$ ). XS thanks the Program for New Century Excellent Talents in University, State Education Ministry, and the Fundação para a Ciência e a Tecnologia and Santander Bank for the Invited Chair in Nanotechnology.

\section{Disclosure}

The authors report no conflicts of interest in this work.

\section{References}

1. Weissleder R, Pittet MJ. Imaging in the era of molecular oncology. Nature. 2008;452(7187):580-589.

2. van Schooneveld MM, Vucic E, Koole R, et al. Improved biocompatibility and pharmacokinetics of silica nanoparticles by means of a lipid coating: a multimodality investigation. Nano Letters. 2008;8(8):2517-2525.

3. Guo R, Wang H, Peng C, et al. X-ray attenuation property of dendrimerentrapped gold nanoparticles. J Phys Chem C. 2010;114(1):50-56.

4. Karfeld-Sulzer LS, Waters EA, Davis NE, Meade TJ, Barron AE. Multivalent protein polymer MRI contrast agents: controlling relaxivity via modulation of amino acid sequence. Biomacromolecules. 2010; 11(6):1429-1436.

5. Schindler TH, Schelbert HR, Quercioli A, Dilsizian V. Cardiac PET imaging for the detection and monitoring of coronary artery disease and microvascular health. JACC Cardiovasc Imaging. 2010;3(6) 623-640.

6. Bhushan KR, Misra P, Liu F, Mathur S, Lenkinski RE, Frangioni JV. Detection of breast cancer microcalcifications using a dual-modality SPECT/NIR fluorescent probe. J Am Chem Soc. 2008;31;130(52) 17648-17649.

7. Barreto JA, O’Malley W, Kubeil M, Graham B, Stephan H, Spiccia L. Nanomaterials: applications in cancer imaging and therapy. Adv Mater. 2011;23(12):H18-H40.

8. Louie A. Multimodality imaging probes: design and challenges. Chem Rev. 2010;110(5):3146-3195.

9. Boisselier E, Astruc D. Gold nanoparticles in nanomedicine: preparations, imaging, diagnostics, therapies and toxicity. Chem Soc Rev. 2009;38(6):1759-1782.

10. Caravan P, Ellison JJ, McMurry TJ, Lauffer RB. Gadolinium(III) chelates as MRI contrast agents: structure, dynamics, and applications. Chem Rev. 1999;99(9):2293-2352.

11. Abujudeh HH, Kaewlai R, Kagan A, et al. Nephrogenic systemic fibrosis after gadopentetate dimeglumine exposure: case series of 36 patients. Radiology. 2009;253(1):81-89.

12. Lim J, Turkbey B, Bernardo M, et al. Gadolinium MRI contrast agents based on triazine dendrimers: relaxivity and in vivo pharmacokinetics. Bioconjug Chem. 2012;23(11):2291-2299.

13. Ratzinger G, Agrawal P, Korner W, et al. Surface modification of PLGA nanospheres with Gd-DTPA and Gd-DOTA for high-relaxivity MRI contrast agents. Biomaterials. 2010;31(33):8716-8723.

14. Zheng J, Liu J, Dunne M, Jaffray DA, Allen C. In vivo performance of a liposomal vascular contrast agent for CT and MR-based image guidance applications. Pharm Res. 2007;24(6):1193-1201.
15. Regino CAS, Walbridge S, Bernardo M, et al. A dual CT-MR dendrimer contrast agent as a surrogate marker for convection-enhanced delivery of intracerebral macromolecular therapeutic agents. Contrast Media Mol Imaging. 2008;3(1):2-8.

16. Alric C, Taleb J, Le Duc G, et al. Gadolinium chelate coated gold nanoparticles as contrast agents for both X-ray computed tomography and magnetic resonance imaging. J Am Chem Soc. 2008;130(18): 5908-5915.

17. Md. NS, Kim H-K, Park J-A, Chang Y, Kim T-J. Gold nanoparticles coated with Gd-Chelate as a potential CT/MRI bimodal contrast agent. Bull Korean Chem Soc. 2010;31(5):1177-1181.

18. Chou SW, Shau YH, Wu PC, Yang YS, Shieh DB, Chen CC. In vitro and in vivo studies of FePt nanoparticles for dual modal CT/MRI molecular imaging. J Am Chem Soc. 2010;132(38):13270-13278.

19. Menjoge AR, Kannan RM, Tomalia DA. Dendrimer-based drug and imaging conjugates: design considerations for nanomedical applications. Drug Discov Today. 2010;15(5-6):171-185.

20. Cheng Y, Wang J, Rao T, He X, Xu T. Pharmaceutical applications of dendrimers: promising nanocarriers for drug delivery. Front Biosci. 2008; 13:1447-1471.

21. Chandrasekar D, Sistla R, Ahmad FJ, Khar RK, Diwan PV. The development of folate-PAMAM dendrimer conjugates for targeted delivery of anti-arthritic drugs and their pharmacokinetics and biodistribution in arthritic rats. Biomaterials. 2007;28(3): 504-512.

22. Bronstein LM, Shifrina ZB. Dendrimers as encapsulating, stabilizing, or directing agents for inorganic nanoparticles. Chem Rev. 2011;111(9): 5301-5344.

23. Peng C, Zheng L, Chen Q, et al. PEGylated dendrimer-entrapped gold nanoparticles for in vivo blood pool and tumor imaging by computed tomography. Biomaterials. 2012;33(4):1107-1119.

24. Wang $\mathrm{H}$, Zheng L, Peng $\mathrm{C}$, et al. Computed tomography imaging of cancer cells using acetylated dendrimer-entrapped gold nanoparticles. Biomaterials. 2011;32(11):2979-2988.

25. Peng C, Wang H, Guo R, et al. Acetylation of dendrimer-entrapped gold nanoparticles: synthesis, stability, and $\mathrm{x}$-ray attenuation properties. J Appl Polym Sci. 2011;119(3):1673-1682.

26. Wen S, Li K, Cai H, et al. Multifunctional dendrimer-entrapped gold nanoparticles for dual mode CT/MR imaging applications. Biomaterials. 2013;34(5):1570-1580.

27. Shi X, Wang S, Sun H, Baker JR Jr. Improved biocompatibility of surface functionalized dendrimer entrapped gold nanoparticles. Soft Matter. 2007;3:71-74.

28. Hong S, Bielinska AU, Mecke A, et al. Interaction of poly(amidoamine) dendrimers with supported lipid bilayers and cells: hole formation and the relation to transport. Bioconjug Chem. 2004;15(4): 774-782.

29. Yang H, Zhang CX, Shi X, et al. Water-soluble superparamagnetic manganese ferrite nanoparticles for magnetic resonance imaging. Biomaterials. 2010;31(13):3667-3673.

30. Lesniak W, Bielinska AU, Sun K, et al. Silver/dendrimer nanocomposites as biomarkers: fabrication, characterization, in vitro toxicity, and intracellular detection. Nano Lett. 2005;5(11):2123-2130.

31. Greish K. Enhanced permeability and retention of macromolecular drugs in solid tumors: a royal gate for targeted anticancer nanomedicines. J Drug Target. 2007;15(7-8):457-464.

32. Greish K. Enhanced permeability and retention (EPR) effect for anticancer nanomedicine drug targeting. Methods Mol Biol. 2010;624: 25-37.

33. Maeda H. Tumor-selective delivery of macromolecular drugs via the EPR effect: background and future prospects. Bioconjug Chem. 2010;21(5):797-802.

34. Maeda H, Bharate GY, Daruwalla J. Polymeric drugs for efficient tumortargeted drug delivery based on EPR-effect. Eur J Pharm Biopharm. 2009;71(3):409-419.

35. Veronese FM, Pasut G. PEGylation, successful approach to drug delivery. Drug Discovery Today. 2005;10(21):1451-1458. 


\section{Supplementary materials}
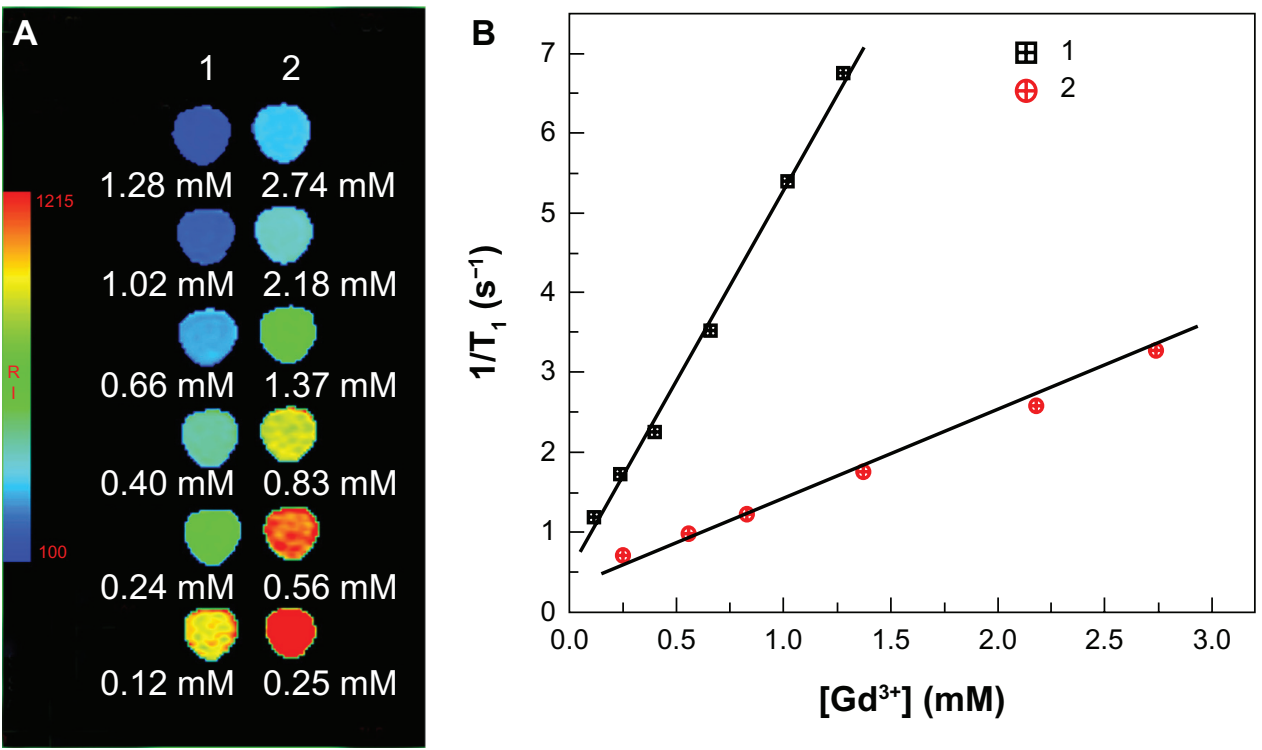

Figure SI Color $T_{1}$-weighted images (A) and linear fitting of $R_{1}(\mathbf{B})$ of G5-Gd (I) and Gd-Au DENPs (2) as a function of Gd concentration. Note: The color bar from red to blue indicates the gradual decrease of the $T_{\text {, }}$ value.

Abbreviations: DENP, dendrimer-entrapped nanoparticle; Gd, gadolinium; Gd-Au DENP, dendrimer-entrapped gold nanoparticle.
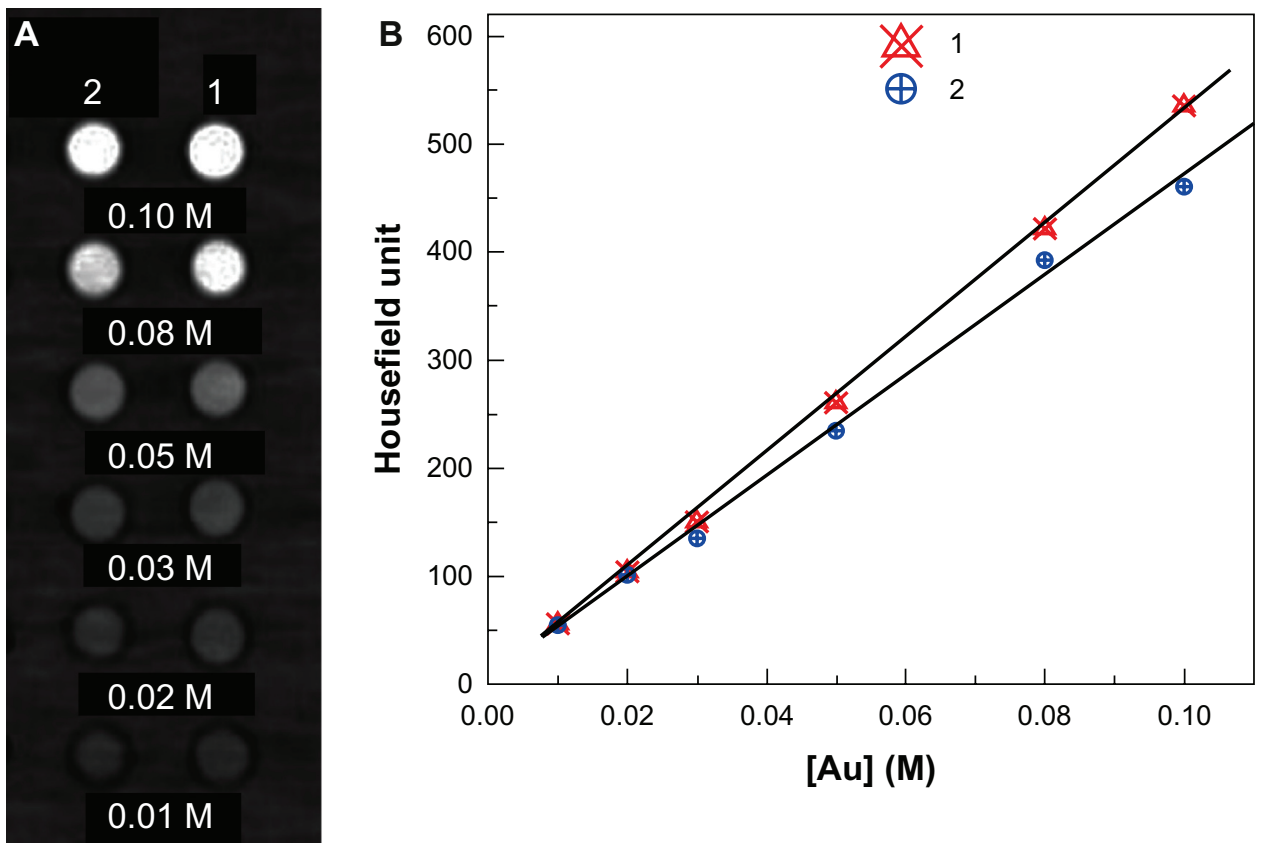

Figure S2 CT phantom images (A) and X-ray attenuation (HU) (B) of Gd-Au DENPs (I) and Au DENPs (2) as a function of gold concentration.

Abbreviations: Au, gold; CT, computed tomography; DENP, dendrimer-entrapped nanoparticle; Gd-Au DENP, dendrimer-entrapped gold nanoparticle; HU, housefield unit. 

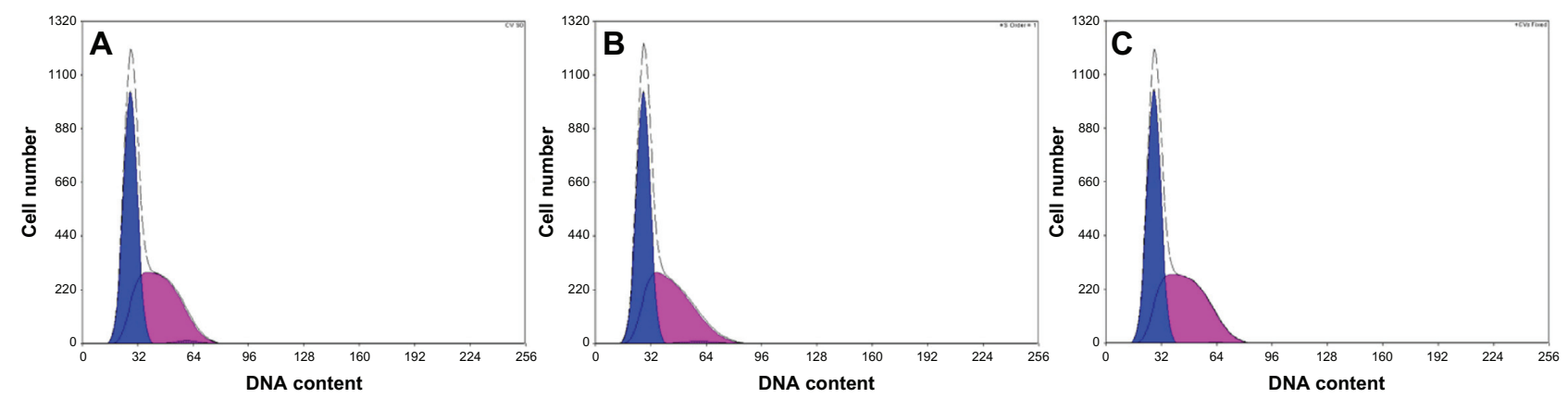

Figure S3 Flow cytometry analysis of MCF-7 cells treated without (A) or with Gd-Au DENPs at concentrations (Au) of $25 \mu M(B)$ and $50 \mu M(C)$ for 4 hours ( $n=4)$. Abbreviations: Au, gold; Gd-Au DENP, dendrimer-entrapped gold nanoparticle.
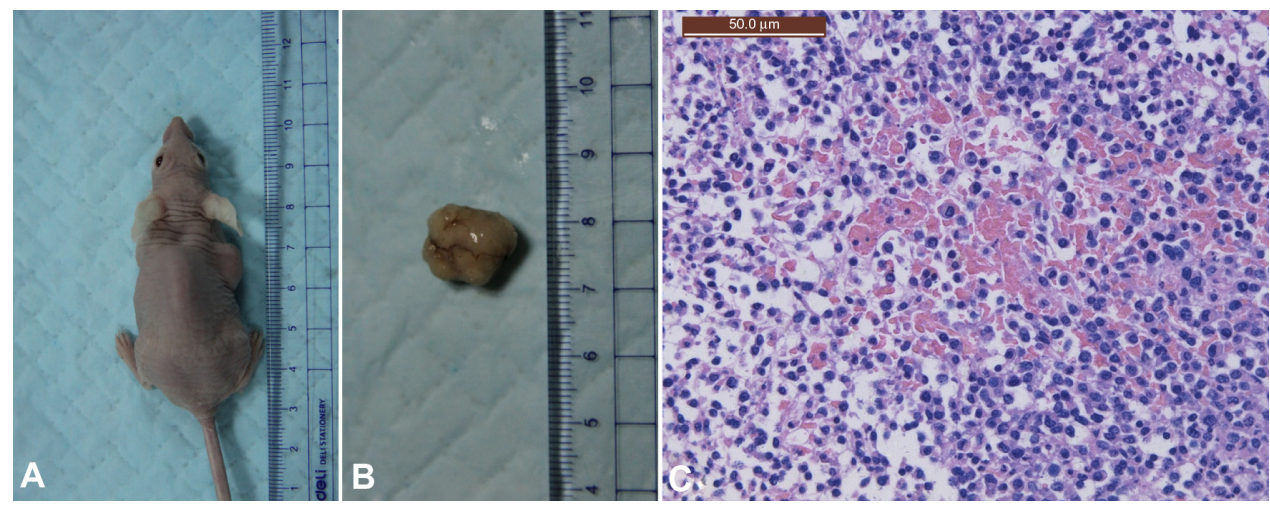

Figure S4 MCF-7 xenografted nude mice models (A), resected tumor (B), and optical microscope image of an HE-stained tumor section (C). Note: The magnification for the tumor section was set at $200 \times$.

Abbreviation: $\mathrm{HE}$, hematoxylin and eosin.

Table SI MR T, relaxation rate and X-ray attenuation properties of Gd-Au DENPs

MR T, relaxation rate and X-ray attenuation properties of Gd-Au DENPs were obtained as previously described.' MR T,-weighted imaging for G5-Gd and Gd-Au DENPs was performed using increasing gadolinium concentrations (Gd; $0.12 \mathrm{mM}, 0.24 \mathrm{mM}, 0.40 \mathrm{mM}, 0.66 \mathrm{mM}, 1.02 \mathrm{mM}$, and I.28 mM for Gd NPs and $0.25 \mathrm{mM}, 0.56 \mathrm{mM}, 0.83 \mathrm{mM}, 1.37 \mathrm{mM}, 2.18 \mathrm{mM}$, and $2.74 \mathrm{mM}$ for the Gd-Au DENPs). Both the G5-Gd and Gd-Au DENPs exerted positive contrast effects in a dose-dependent manner, as shown in Figure SI. However, the $T_{1}$ relaxivities (the slope of the graph of I/T $T_{1}$ ) of the G5-Gd and Gd-Au DENPs were $4.82 \mathrm{mM}^{-1} \mathrm{~s}^{-1}$ and $1.04 \mathrm{mM}^{-1} \mathrm{~s}^{-1}$, respectively (Figure SIB), which means that the T, relaxivities of the Gd-Au DENPs were reduced compared to the G5-Gd. This result indicated that there is most likely an interaction between the Gd and gold nanoparticles, which requires further intensive study.

CT images of phantoms containing Gd-Au DENPs and Au DENPs at various gold concentrations ( $10 \mathrm{mM}, 20 \mathrm{mM}, 30 \mathrm{mM}, 50 \mathrm{mM}, 80 \mathrm{mM}, 100 \mathrm{mM}$ ) revealed that these particles clearly result in X-ray attenuation, even when the gold concentration is only $10 \mathrm{mM}$ (Figure S2). As expected, significant dose-dependent inverse CT image contrast was observed in both arrays (Figure S2), which is consistent with our previous report. ${ }^{2}$ Compared with the arrays of Au DENPs, the Gd-Au DENPs exerted a better contrast effect with the same gold concentrations in the experiment, likely the existence of $\mathrm{Gd}^{3+}$, which may contribute to a small additional amount of X-ray attenuation within the $\mathrm{CT}$ images, although the Gd K-edge energy $(50.2 \mathrm{KeV})$ is considerably lower than that of gold $(80.7 \mathrm{KeV}){ }^{3,4}$

Abbreviations: $\mathrm{Au}$, gold; $\mathrm{CT}$, computed tomography; Gd, gadolinium; Gd-Au DENP, dendrimer-entrapped gold nanoparticle; Gd ${ }^{3+}$; $\mathrm{MR}$, magnetic resonance; NP, nanoparticle.

Table S2 Histology study

After the final MR and CT scan, each mouse was deeply anesthetized, and the tumor was resected. The tumor tissues were postfixed with $4 \%$ paraformaldehyde in a $0.1 \mathrm{M}$ phosphate buffer $(\mathrm{pH} 7.4)$ for 24 hours, and then dehydrated, embedded, and sectioned into $3 \mu \mathrm{m}$-thick slices. After being dewaxed and rehydrated, the tumor sections were stained with hematoxylin and eosin.

Abbreviations: CT, computed tomography; MR, magnetic resonance. 


\section{References}

1. Wen S, Li K, Cai H, et al. Multifunctional dendrimer-entrapped gold nanoparticles for dual mode CT/MR imaging applications. Biomaterials. 2013;34(5):1570-1580.

2. Shi $X$, Wang $S$, Sun $H$, Baker JR Jr. Improved biocompatibility of surface functionalized dendrimer entrapped gold nanoparticles. Soft Matter. 2007;3:71-74.
3. Alric C, Taleb J, Le Duc G, et al. Gadolinium chelate coated gold nanoparticles as contrast agents for both X-ray computed tomography and magnetic resonance imaging. J Am Chem Soc. 2008;130: $5908-5915$.

4. Md NS, Kim H-K, Park J-A, Chang Y, Kim T-J. Gold nanoparticles coated with Gd-chelate as a potential CT/MRI bimodal contrast agent. Bull Korean Chem Soc. 2010;31(5):1177-1181.

\section{Publish your work in this journal}

The International Journal of Nanomedicine is an international, peerreviewed journal focusing on the application of nanotechnology in diagnostics, therapeutics, and drug delivery systems throughout the biomedical field. This journal is indexed on PubMed Central, MedLine, CAS, SciSearch ${ }^{\circledR}$, Current Contents ${ }^{\circledR} /$ Clinical Medicine,
Journal Citation Reports/Science Edition, EMBase, Scopus and the Elsevier Bibliographic databases. The manuscript management system is completely online and includes a very quick and fair peer-review system, which is all easy to use. Visit http://www.dovepress.com/ testimonials.php to read real quotes from published authors. 